\section{Autoantikörper gegen neuronale Zellkerne Typ 3}

\section{W. Stöcker}

Euroimmun Medizinische Labordiagnostika AG, Lübeck, Deutschland

\section{Synonym(e) ANNA-3}

Englischer Begriff ANNA-3 autoantibodies; anti-neuronal nuclear antibodies type 3

Definition Autoantikörper gegen ein 170-kDa-Protein in den Zellkernen der Purkinje-Zellen des Kleinhirns (das auch in den Podozyten der Nierenglomeruli exprimiert wird).

Funktion - Pathophysiologie ANNA-3-Proteine werden sowohl in peripheren und zentralen Neuronen exprimiert als auch, bei Antikörper-positiven Patienten, in Tumorgewebe.

Probenstabilität Autoantikörper sind bei $+4{ }^{\circ} \mathrm{C}$ bis zu 2 Wochen lang beständig, bei $-20^{\circ} \mathrm{C}$ über Monate und Jahre hinweg.

Analytik Der Nachweis von Autoantikörpern gegen neuronale Zellkerne Typ 3 ist mit dem indirekten Immunfluores- zenztest (IIFT, \ Immunfluoreszenz, indirekte) mit Gefrierschnitten von Primatenkleinhirn möglich. Autoantikörper gegen neuronale Zellkerne Typ 3 zeigen eine Fluoreszenz der Purkinje-Zell-Nuclei sowie der Podozyten der Nierenglomeruli.

Im $>$ Western blot mit aufgetrenntem Kleinhirnextrakt kommt es zu einer Reaktion bei $170 \mathrm{kDa}$.

ANNA-3 werden wegen der differenzialdiagnostischen Verwandtschaft der assoziierten Enzephalitis zu anderen paraneoplastischen neurologischen Syndromen parallel zu den übrigen $>$ Autoantikörpern gegen neuronale Antigene untersucht.

Untersuchungsmaterial Serum, Plasma oder Liquor.

Diagnostische Wertigkeit ANNA-3 werden bei zerebellarer Ataxie, Myelopathie und limbischer/Hirnstamm-Enzephalitis gefunden, sie sind mit kleinzelligen Bronchialkarzinomen und Adenokarzinomen assoziiert und können den ersten Hinweis auf einen zugrunde liegenden Tumor geben.

\section{Literatur}

Chan KH, Vernino S, Lennon VA (2001) ANNA-3 anti-neuronal antibody: marker of lung cancer-related autoimmunity. Ann Neurol 50:301-311 